\title{
Produção de minitubérculos de batata semente básica em hidroponia em função de doses de nitrogênio ${ }^{1}$
}

\author{
Basic seed potato yield in hydroponic systems as a function of $\mathrm{N}$ rates
}

\author{
Carla de Bem Santos Souza 2 , Paulo Cezar Rezende Fontes ${ }^{2}$, Marialva Alvarenga Moreira ${ }^{3 *}$, Paulo Roberto \\ Cecon $^{2}$ e Mario Puiatti ${ }^{2}$
}

\begin{abstract}
RESUMO - A dose ótima de nitrogênio (N) na cultura da batata depende do sistema de produção. O objetivo do trabalho foi determinar a dose ótima de $\mathrm{N}$ para a produção de minitubérculos de batata-semente básica em hidroponia e verificar o desenvolvimento da planta no sistema hidropônico em plataforma de telha amianto. O experimento foi realizado em ambiente protegido, no Departamento de Fitotecnia da Universidade Federal de Viçosa, utilizando o plantio de broto da cultivar Asterix. Os tratamentos foram constituídos por quatro doses de $\mathrm{N}\left(45 ; 90 ; 180\right.$ e $\left.270 \mathrm{mg} \mathrm{L}^{-1}\right)$, sendo $10 \%$ de cada dose de $\mathrm{N}$ aplicadas na forma de nitrato de amônio $\left(\mathrm{N}_{-} \mathrm{NH}_{4}^{+}\right)$e o restante de $\mathrm{N}$ na forma de nitrato de cálcio e nitrato de potássio. O maior número (14,1 tubérculos/planta) e a máxima massa de tubérculos $(68,4 \mathrm{~g} / \mathrm{planta})$ foram obtidos com 188,9 e $270 \mathrm{mg} \mathrm{L}^{-1}$ de $\mathrm{N}$, respectivamente. Portanto, número e massa de tubérculos não foram otimizados pela mesma dose de N. O índice crítico SPAD na quarta folha é variável com a idade da planta sendo de 38,4 o maior valor atingido aos 58 DAT.
\end{abstract}

Palavras-chave: Batata. Hidroponia. Clorofilômetro. Plantas-efeito do nitrogênio.

\begin{abstract}
The optimal nitrogen (N) rate for potato crops depends on the production system. The objective of this study was to determine the optimal rate of $\mathrm{N}$ for the production of minitubers of the basic seed potato grown hydroponically, and to verify the development of the plant in a hydroponic system using a platform of asbestos tiles. The experiment was conducted in a greenhouse at the Department of Plant Science of the Federal University of Viçosa, using shoots of the Asterix cultivar. The treatments consisted of four levels of $\mathrm{N}\left(45,90,180\right.$ and $\left.270 \mathrm{mg} \mathrm{L}^{-1}\right)$, with $10 \%$ of each dose of $\mathrm{N}$ being applied as ammonium nitrate $\left(\mathrm{N} \mathrm{NH}_{4}^{+}\right)$and the remainder in the form of calcium nitrate and potassium nitrate. The largest number (14.1 tubers per plant) and the maximum weight of tubers ( $68.4 \mathrm{~g}$ per plant) were obtained with 188.9 and $270 \mathrm{mg} \mathrm{L}^{-1} \mathrm{~N}$ respectively. Therefore, the number and weight of tubers were not optimized by the same rate of $\mathrm{N}$. The critical SPAD index in the fourth leaf varies with the age of the plan,t with 38.4 being the largest value reached at $58 \mathrm{DAT}$.
\end{abstract}

Key words: Potato. Hydroponic systems. Chlorophyll meter. Plant nutrition of nitrogen.

\footnotetext{
*Autor para correspondência

${ }^{1}$ Recebido para publicação em 04/05/2012; aprovado em 07/06/2013

Pesquisa realizada com o apoio do CNPq e FAPEMIG

2Departamento de Fitotecnia, Universidade Federal de Viçosa, Av. P.H. Rolfs, Centro, Viçosa-MG, Brasil, 36.571-000, bemsantos@ yahoo.com.br, pacerefo@ufv.br, cecon@dpi.ufv.br,mpuiatti@ufv.br

${ }^{3}$ Departamento de Fitotecnia, Universidade Federal de Viçosa, Av. P.H. Rolfs, Centro, Viçosa-MG, Brasil 36.571-000, marialvamoreira@ yahoo.com.br
} 


\section{INTRODUÇÃO}

A batata-semente básica utilizada no Brasil pode ser obtida de duas formas, importada de vários países como Holanda, Canadá, Argentina e Alemanha ou produzida internamente via cultura de tecidos. Uma forma de reduzir a importação é a utilização de brotos destacados de batata-semente.

O uso do broto como material de propagação foi pioneiramente proposto e tem sido defendido no Brasil por Souza-Dias (2004; 2006a, 2006b), pois reduz a importação e propicia aumento de até $200 \%$ na produção de minitubérculos da categoria básica (SOUZA-DIAS, 2006b), sem a utilização de mão-de-obra especializada, como a propagação in vitro que precisa de laboratório, ambiente e procedimento de aclimatação de plântulas ou muda em telados e de repicagens constantes (SILVA; GIUSTO; SOUZA-DIAS, 2006).

A hidroponia é um método em que se cultiva sem a presença de solo, permitindo a colheita dos tubérculos de forma única ou escalonada, além de possibilitar a redução da contaminação da semente por patógenos de solo. Também, com a hidroponia é possível maior controle da aplicação de nutrientes (CORRÊA et al., 2008).

No Brasil, resultados encontrados até o momento com hidroponia revelam importantes avanços no processo produtivo de batata-semente no que diz respeito à taxa de multiplicação (CORRÊA et al., 2009; FACTOR et al., 2007; MEDEIROS et al., 2002). São raros os estudos relacionando hidroponia, nitrogênio e batata. Qualquer que seja o sistema utilizado na produção de sementes básicas de batata, quase sempre, é necessária a adição de $\mathrm{N}$.

$\mathrm{O} \mathrm{N}$ é importante para otimização da produção e qualidade dos tubérculos (WU et al., 2007). Dose elevada de $\mathrm{N}$ pode propiciar menor número de tubérculo por planta (MEDEIROS; CUNHA, 2003). Entretanto, as variações climáticas entre localidades modificam o crescimento, desenvolvimento e partição de assimilados na batateira, além da possibilidade de ocorrer interação genótipo e ambiente que podem modificar a resposta às doses de $\mathrm{N}$.

O monitoramento do estado nitrogenado de plantas é realizado por vários índices, o mais tradicional é a análise do teor de $\mathrm{N}$ na matéria-seca de folhas, sendo oneroso e demorado, podendo ser substituído por testes rápidos em tempo real (FONTES, 2011). Os índices mais comuns de $\mathrm{N}$ na planta, possíveis de serem realizados em tempo real, são as variáveis biométricas da planta: comprimento, largura, massa fresca e área foliar da quarta folha. Adicionalmente, há a possibilidade de medir o valor de intensidade do verde da folha por medidor portátil, que proporciona leitura instantânea, de maneira não destrutiva de folhas (FONTES, 2011).
Apesar de existirem trabalhos que procuram estabelecer índices para avaliar o estado de $\mathrm{N}$ da batateira (BUSATO et al., 2010; BRAUN et al., 2010; COELHO et al., 2010; FONTES et al., 2010; SILVA et al., 2011; SILVA; FONTES; MIRANDA, 2009) e no manejo do $\mathrm{N}$ na produção de minitubérculos em vaso contendo substrato (MOREIRA et al., 2011; SAMPAIO JÚNIOR et al., 2008), são raros ou inexistentes trabalhos que procuram determinar o valor crítico destes índices no sistema de produção de batata-semente básica multiplicada por broto em sistema hidropônico. Neste sentido, avaliar o efeito de $\mathrm{N}$ em hidroponia e multiplicação por broto torna-se uma necessidade.

Assim, o objetivo deste trabalho foi determinar a dose ótima de $\mathrm{N}$ para a produção de minitubérculos e verificar o desenvolvimento da batateira em sistema hidropônico, em plataforma de telha amianto utilizando o broto como material de propagação.

\section{MATERIAL E MÉTODOS}

O experimento com batata-semente (Solanum tuberosum L.) em sistema hidropônico foi conduzido em ambiente protegido do Departamento de Fitotecnia da Universidade Federal de Viçosa. A estrutura de proteção seguiu o modelo capela, com largura de 9,0 m, comprimento de 40,0 m, altura dos esteios laterais de 3,0 $\mathrm{m}$, altura do vão central de $3,8 \mathrm{~m}$, com as partes superiores, frontais e laterais fechadas com filme de polietileno de baixa densidade transparente de $0,1 \mathrm{~mm}$ de espessura.

Os tratamentos foram constituídos pelas doses de N (45; 90; 180 e $\left.270 \mathrm{mg} \mathrm{L}^{-1}\right)$, sendo que $10 \%$ de cada dose de $\mathrm{N}$ foi fornecida na forma de nitrato de amônio $\left(\mathrm{N}-\mathrm{NH}_{4}^{+}\right)$e o restante de $\mathrm{N}$ na forma de nitrato de cálcio e nitrato de potássio. $\mathrm{O}$ delineamento experimental utilizado foi de blocos ao acaso, com seis repetições. Cada parcela experimental foi constituída de quatro plantas úteis.

O broto, cultivar Asterix foi destacado de batata-semente básica e desinfetado seguindo a metodologia descrita por Bryan, Meléndez e Jackson (1981). Posteriormente, os brotos foram plantados em bandejas de poliestireno de 128 células, contendo areia lavada como substrato, onde permaneceram por 20 dias. As mudas foram transplantadas para o sistema hidropônico de telhas de fibrocimento preenchidas com brita conforme descrito por Medeiros et al. (2000). O espaçamento foi de $10 \mathrm{~cm}$ entre plantas e $18 \mathrm{~cm}$ entre fileiras.

A solução nutritiva utilizada foi descrita por Andriolo (2006) com modificação para a concentração 
de N. A circulação da solução para cada tratamento foi realizada por um conjunto moto-bomba de $0,5 \mathrm{HP}$ e controlada por um temporizador, o qual manteve a circulação por 30 minutos a intervalos de 15 minutos durante o dia e, durante a noite 15 minutos ligados a intervalos de 30 minutos. $\mathrm{O}$ pH da solução foi ajustado diariamente, mantendo-o entre 5 e 5,5 utilizando-se $\mathrm{HCl}$ ou $\mathrm{NaOH}$ 1N. A troca da solução nutritiva ocorreu quando houve redução da condutividade elétrica, admitiu-se até $30 \%$ de depleção da solução usada em pelo menos um dos tratamentos.

Aos 23 dias após o transplante (DAT) das mudas para o sistema hidropônico iniciaram-se as avaliações que, posteriormente, ocorreram a cada sete dias até a colheita final. As determinações feitas foram: intensidade da cor verde da folha, comprimento, largura e número de folíolos da quarta folha $(\mathrm{QF})$ e folha velha $(\mathrm{FV})$, comprimento da haste e número de folhas da batateira. A intensidade do verde da folha foi determinada no folíolo terminal da QF e FV, entre 8 e 11 horas, com o medidor portátil de clorofila denominado SPAD-502 (Soil Plant Analysis Development-502).

A colheita final ocorreu aos 79 DAT. As plantas foram colhidas, separadas em quarta folha, folha velha, folhas, hastes, raízes e tubérculos. Determinou-se a área foliar e as partes foram pesadas para determinação da massa da matéria fresca, e posteriormente após secagem determinou-se a massa da matéria seca. Os tubérculos foram contados e classificados de acordo com maior diâmetro em tipos, V (16 a $23 \mathrm{~mm})$, VI (13 a $16 \mathrm{~mm})$, VII (10 a $13 \mathrm{~mm})$ e VIII (< $10 \mathrm{~mm})$, conforme padrões recomendados pelo Instituto Mineiro de Agropecuária (2003). Após a secagem, as massas secas da quarta folha e folha velha foram moídas em moinho tipo Willy, equipado com peneira de 20 mesh, para a determinação do teor de N, após digestão sulfúrica, utilizando-se o reagente Nessler (JACKSON, 1958). Em outra subamostra, o N-NO foi extraído com água desmineralizada em banho-maria, a $45^{\circ} \mathrm{C}$ por $1 \mathrm{~h}$, determinando-se a concentração de $\mathrm{N}$ $\mathrm{NO}_{3}$ por colorimetria, em espectrofotômetro a $410 \mathrm{~nm}$ (CATALDO et al., 1975).

Os dados foram submetidos às análises de variância e de regressão, utilizando-se o programa SAEG (SISTEMA..., 2007). Para cada época de amostragem foi ajustado um modelo que melhor descrevesse a relação entre os valores da variável avaliada e de doses de nitrogênio. Nesse modelo foi introduzido o valor da dose ótima de $\mathrm{N}$, obtendo-se o valor do nível crítico ou valor ótimo de cada variável em cada época de amostragem (FONTES, 2011). Foi considerada dose ótima de $\mathrm{N}$ aquela que propiciou o número máximo de tubérculos.

\section{RESULTADOS E DISCUSSÃO}

Houve efeito de doses de $\mathrm{N}$ e de épocas de avaliação sobre a intensidade da cor verde da QF e FV determinada pelo índice SPAD (Tabela 1). Ao longo do ciclo da cultura houve uma ascensão e queda no valor do índice SPAD na QF e FV, ocorrendo a ascensão até aos 51 DAT e queda a partir dos 58 DAT. Aumento em SPAD significa aumento na intensidade da cor verde da planta e, segundo Fontes (2011), o índice SPAD mede de forma indireta o teor de clorofila, indicando o estado de nitrogênio da planta. Decréscimo do índice SPAD no decorrer do período de cultivo da batateira também foi verificado por outros autores (CARDOSO et al., 2011; MOREIRA et al., 2011; RODRIGUES, 2004; SAMPAIO JÚNIOR et al., 2008). RASTAMI et al. (2008) obtiveram ascensão e queda no valor do índice SPAD ao longo do ciclo da cultura do milho e chamaram de "maturidade fotossintética" o ponto de máximo teor de clorofila o qual, não necessariamente, corresponde ao máximo de tamanho da folha.

O modelo da equaçãorelacionando valor doíndice SPAD e ciclo da cultura depende da disponibilidade de $\mathrm{N}$ no estádio inicial da cultura, determinado pela dose de $\mathrm{N}$ aplicada no plantio. Observou-se que dos 23 aos 37 DAT o valor SPAD não foi afetado por doses de $\mathrm{N}$, indicando que mesmo as menores concentrações de $\mathrm{N}$ na solução nutritiva forneciam $\mathrm{N}$ suficiente às plantas. Dos 44 a 51 DAT a maior dose de $\mathrm{N}$ ainda estava propiciando valor linear do índice SPAD na QF e FV, indicando que neste período a dose de $\mathrm{N}$ pode ser aumentada de $270 \mathrm{mg} \mathrm{L}^{-1}$. De 58 até 79 DAT os valores ótimos de SPAD foram declinando (Tabela 1). Assim, com base no índice SPAD, até os 37 DAT poderia utilizar doses baixas de $\mathrm{N}$, por exemplo, $45 \mathrm{mg} \mathrm{L}^{-1}$, dose maior que $270 \mathrm{mgL}^{-1}$ de 44 aos 51 DAT e após aos 51 DAT doses menores.

Com a dose de $\mathrm{N}$ que proporcionou o número máximo de tubérculos (188,9 $\mathrm{mg} \mathrm{L}^{-1}$ de $\left.\mathrm{N}\right)$, o índice SPAD na QF, aos 58 DAT atingiu o valor ótimo máximo de 38,4 unidades; após esta época o valor decresceu o que pode ter ocorrido devido à intensa tuberização nesse período, quando as reservas de $\mathrm{N}$ das folhas começam a ser translocadas para a produção de tubérculos. Na FV, o valor ótimo máximo do índice SPAD foi de 34,6 unidades, aos 44 DAT (Tabela 2). Isso pode ser explicado pela remobilização do nitrogênio na planta, da folha mais velha para as mais novas, bem como os fotoassimilados estão sendo solicitados pelos drenos como estolão e tubérculos, que estão sendo formados durante o ciclo da batateira.

Em avaliações realizadas aos 23; 30; 37 e 44 DAT, os valores estimados do índice SPAD associados à dose de $\mathrm{N}$ que propiciou a máxima produção de tubérculos 
Tabela 1 - Equações ajustadas para o índice SPAD medido na quarta folha e folha velha da batateira aos $23 ; 30 ; 37 ; 44 ; 51 ; 58 ; 65 ; 72$ e 79 dias após o transplantio em função das doses de nitrogênio $(\mathrm{N})$, e os respectivos coeficientes de determinação

\begin{tabular}{|c|c|c|}
\hline \multirow{2}{*}{ Características } & Equações ajustadas & \multirow{2}{*}{$\mathrm{R}^{2} / \mathrm{r}^{2}$} \\
\hline & - & \\
\hline SPAD23 & $\hat{\mathrm{Y}}=22,1$ & --- \\
\hline SPAD30 & $\hat{Y}=28,8$ & --- \\
\hline SPAD37 & $\hat{Y}=27,9$ & --- \\
\hline SPAD44 & $\hat{\mathrm{Y}}=26,3757+0,04241682 * * \mathrm{~N}$ & 0,95 \\
\hline SPAD51 & $\hat{\mathrm{Y}}=29,7619+0,03097301 * * \mathrm{~N}$ & 0,92 \\
\hline SPAD58 & $\hat{\mathrm{Y}}=26,7395+0,11612181 * * \mathrm{~N}-0,00028841 * * \mathrm{~N}^{2}$ & 0,67 \\
\hline SPAD65 & $\hat{\mathrm{Y}}=26,1154+0,12136795^{* *} \mathrm{~N}-0,00032095^{* *} \mathrm{~N}^{2}$ & 0,99 \\
\hline SPAD72 & $\hat{\mathrm{Y}}=19,6420+0,16958961 * * \mathrm{~N}-0,00045927 * * \mathrm{~N}^{2}$ & 0,99 \\
\hline \multirow[t]{2}{*}{ SPAD79 } & $\hat{\mathrm{Y}}=15,4488+0,20970268 * * \mathrm{~N}-0,0005883 * * \mathrm{~N}^{2}$ & 0,96 \\
\hline & 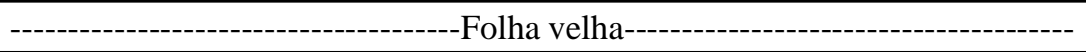 & \\
\hline SPAD23 & $\hat{\mathrm{Y}}=22,3$ & $\begin{array}{c}-- \\
-1\end{array}$ \\
\hline SPAD30 & $\hat{Y}=31,2$ & --- \\
\hline SPAD37 & $\hat{\mathrm{Y}}=32,4$ & --- \\
\hline SPAD44 & $\hat{\mathrm{Y}}=29,3568+0,02764595 * \mathrm{~N}$ & 0,77 \\
\hline SPAD51 & $\hat{\mathrm{Y}}=31,9286+0,01059636^{*} \mathrm{~N}$ & 0,62 \\
\hline SPAD58 & $\hat{\mathrm{Y}}=24,8343+0,08733157 * \mathrm{~N}-0,00026793 * \mathrm{~N}^{2}$ & 0,89 \\
\hline SPAD65 & $\hat{\mathrm{Y}}=20,9231+0,12955193^{* *} \mathrm{~N}-0,00042998^{* *} \mathrm{~N}^{2}$ & 1,00 \\
\hline SPAD72 & $\hat{\mathrm{Y}}=14,2519+0,16447655^{* *} \mathrm{~N}-0,00054012^{* *} \mathrm{~N}^{2}$ & 0,95 \\
\hline SPAD79 & $\hat{\mathrm{Y}}=12,1093+0,12950819 * * \mathrm{~N}-0,00030799 * \mathrm{~N}^{2}$ & 0,96 \\
\hline
\end{tabular}

** e* - significativos a 1 e 5\% pelo teste "t", respectivamente

apresentaram-se inferiores na $\mathrm{QF}$, quando comparados aos valores estimados na FV. Porém, a partir dos 51 DAT, a situação foi inversa, sendo maiores os valores do índice SPAD obtidos na QF (Tabela 2). Isto pode ser explicado pela remobilização do $\mathrm{N}$ das folhas mais velhas para as mais novas, o que ocorreu mais acentuadamente nos tratamentos que receberam menores doses de $\mathrm{N}$ em pré-plantio. Andriolo et al. (2006) relataram que a maior concentração de N está nas folhas mais jovens e ocorre remobilização deste nutriente no decorrer do ciclo de crescimento e desenvolvimento da planta. $\mathrm{O}$ índice SPAD na folha velha também pode ser indicativo da necessidade da aplicação do $\mathrm{N}$, desde que se conheça o nível crítico abaixo do qual a planta estaria deficiente neste elemento, embora existam outros fatores que interferem no índice SPAD, como por exemplo, a cultivar utilizada (BUSATO et al., 2010).

Todas as variáveis relacionadas com as características de desenvolvimento da QF foram influenciadas pela dose de $\mathrm{N}$ e as épocas de avaliações (Tabela 3; 4 e 5). À medida que aumentou a dose de $\mathrm{N}$ houve um incremento quanto ao comprimento, largura e o número de folíolos da $\mathrm{QF}$, comprovando que o $\mathrm{N}$ interfere no desenvolvimento da folha. Houve efeito de doses de $\mathrm{N}$ sobre o comprimento e largura da folha velha ao longo do ciclo de cultivo, enquanto que o número de folíolos da folha velha houve efeito da dose de nitrogênio apenas aos 65 DAT (Tabela 3; 4 e 5).

O comprimento da haste aumentou ao longo do ciclo de cultivo da batateira e apresentou, em todas as épocas de avaliações, resposta linear à aplicação de $\mathrm{N}$ (Tabela 6). Com a dose de $\mathrm{N}$ que proporcionou o número máximo de tubérculos $\left(188,9 \mathrm{mg} \mathrm{L}^{-1}\right.$ de $\mathrm{N}$ ) o comprimento da haste atingiu, aos 79 DAT o valor ótimo estimado de 22,4 cm (Tabela 2). Resultado superior ao encontrado por Moreira et al. (2011) que obteve comprimento da haste de $16,7 \mathrm{~cm}$ aos 80 dias após o plantio em vaso, demonstrando que a planta de batata se adaptou ao sistema hidropônico, pelo menos no que diz respeito ao comprimento da haste.

$\mathrm{O}$ número de folhas apresentou resposta linear à aplicação de $\mathrm{N}$ até aos 44 DAT, a partir desta data, o número de folha aumentou, mas não houve resposta à aplicação de 
Tabela 2 - Valores ótimos do índice SPAD, comprimento (C), largura (L), número de folíolos (NFo) na quarta folha (QF) e folha velha $(\mathrm{FV})$, e das características agronômicas da planta comprimento da haste $(\mathrm{CH})$ e número de folhas (NF) avaliadas durante o ciclo de cultivo da batateira em sistema hidropônico

\begin{tabular}{lccccccccc}
\hline \multirow{2}{*}{ Características } & \multicolumn{8}{c}{ Ciclo da batateira (Dias após o transplante) } \\
\cline { 2 - 10 } & 23 & 30 & 37 & 44 & 51 & 58 & 65 & 72 & 79 \\
\hline SPAD QF & 22,1 & 28,8 & 27,9 & 34,4 & 35,6 & 38,4 & 37,6 & 35,3 & 34,1 \\
SPAD FV & 22,3 & 31,2 & 32,4 & 34,6 & 33,9 & 31,8 & 30,1 & 26,1 & 25,6 \\
CQF (cm) & 5,63 & 8,79 & 10,72 & 12,32 & 10,61 & 10,70 & 10,32 & 9,87 & 9,98 \\
LQF (cm) & 3,53 & 5,38 & 7,23 & 8,38 & 8,72 & 9,00 & 8,07 & 7,73 & 8,30 \\
NFoQF(unidade) & 2,80 & 3,00 & 4,40 & 5,10 & 5,80 & 5,40 & 6,70 & 6,00 & 6,20 \\
CFV (cm) & 5,10 & 4,70 & 5,55 & 6,35 & 7,02 & 7,69 & 7,81 & 9,12 & 9,72 \\
LFV (cm) & 1,90 & 2,80 & 3,44 & 3,90 & 4,43 & 4,50 & 4,21 & 5,10 & 5,82 \\
NFoFV(unidade) & 1,00 & 1,00 & 2,00 & 2,00 & 2,00 & 3,00 & 3,00 & 3,00 & 3,00 \\
CH (cm) & 8,09 & 11,86 & 15,27 & 18,39 & 20,43 & 21,05 & 21,51 & 22,07 & 22,37 \\
NF (unidade) & 6,40 & 9,10 & 11,40 & 13,40 & 16,00 & 18,00 & 21,00 & 22,00 & 29,00 \\
\hline
\end{tabular}

Tabela 3 - Equações ajustadas para o comprimento (C) medido na quarta folha e folha velha da batateira aos 23; 30; 37; 44; $51 ; 58 ; 65 ; 72$ e 79 dias após o transplante em função das doses de nitrogênio $(\mathrm{N})$, e os respectivos coeficientes de determinação

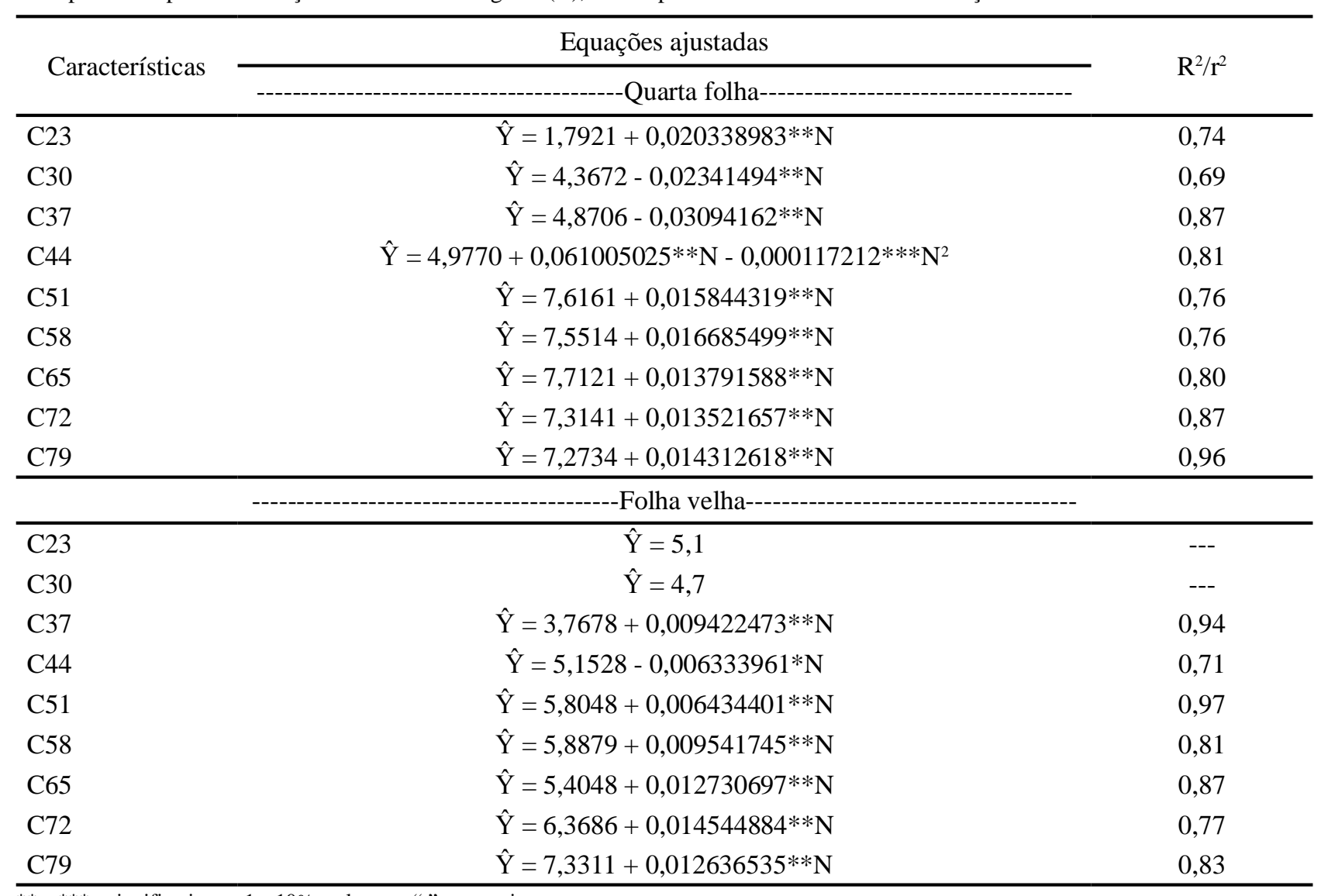

** $\mathrm{e}^{* * *}$ - significativos a 1 e $10 \%$ pelo teste " $\mathrm{t}$ ", respectivamente 
Tabela 4 - Equações ajustadas para a largura (L) medido na quarta folha e folha velha da batateira aos 23; 30; 37; 44; 51; 58; 65; 72 e 79 dias após o transplante em função das doses de nitrogênio $(\mathrm{N})$, e os respectivos coeficientes de determinação

\begin{tabular}{|c|c|c|}
\hline \multirow{2}{*}{ Características } & Equações ajustadas & \multirow{2}{*}{$\mathrm{R}^{2} / \mathrm{r}^{2}$} \\
\hline & - & \\
\hline $\mathrm{L} 23$ & $\hat{\mathrm{Y}}=1,2144+0,012266164 * * \mathrm{~N}$ & 0,76 \\
\hline L30 & $\hat{\mathrm{Y}}=2,7093+0,014124294 * * \mathrm{~N}$ & 0,69 \\
\hline L37 & $\hat{\mathrm{Y}}=3,0011+0,022385436 * * \mathrm{~N}$ & 0,91 \\
\hline L44 & $\hat{\mathrm{Y}}=4,6432+0,019761456 * * \mathrm{~N}$ & 0,87 \\
\hline L51 & $\hat{\mathrm{Y}}=2,7542+0,052847571 * * \mathrm{~N}-0,000112621 * \mathrm{~N}^{2}$ & 0,71 \\
\hline L58 & $\hat{Y}=3,5162+0,048232366 * * N-0,00010163 * \mathrm{~N}^{2}$ & 0,74 \\
\hline L65 & $\hat{\mathrm{Y}}=5,8458+0,011795355^{* *} \mathrm{~N}$ & 0,83 \\
\hline L72 & $\hat{\mathrm{Y}}=5,3983+0,01234772 * * \mathrm{~N}$ & 0,98 \\
\hline \multirow[t]{2}{*}{ L79 } & $\hat{\mathrm{Y}}=4,2827+0,033136981 * * \mathrm{~N}-0,000062804 * * * \mathrm{~N}^{2}$ & 0,91 \\
\hline & -Folha velha--- & \\
\hline $\mathrm{L} 23$ & $\hat{\mathrm{Y}}=1,9$ & --- \\
\hline L30 & $\hat{\mathrm{Y}}=2,8$ & --- \\
\hline L37 & $\hat{\mathrm{Y}}=2,6322+0,00428123 * \mathrm{~N}$ & 0,77 \\
\hline L44 & $\hat{Y}=3,9$ & --- \\
\hline L51 & $\hat{\mathrm{Y}}=3,8073+0,003283114 * * * \mathrm{~N}$ & 0,95 \\
\hline L58 & $\hat{Y}=4,5$ & --- \\
\hline L65 & $\hat{\mathrm{Y}}=4,5700-0,01262935^{* * *} \mathrm{~N}+0,000056817 * \mathrm{~N}^{2}$ & 0,85 \\
\hline L72 & $\hat{Y}=5,1$ & --- \\
\hline L79 & $\hat{\mathrm{Y}}=4,4613+0,007187696^{*} \mathrm{~N}$ & 0,73 \\
\hline
\end{tabular}

**, * e***-significativos a $1 ; 5$ e $10 \%$ pelo teste " $\mathrm{t}$ ", respectivamente

Tabela 5 - Equações ajustadas para o número de folíolos (NFo) medido na quarta folha e folha velha da batateira aos 23; 30; 37; 44; 51; 58; 65; 72 e 79 dias após o transplante em função das doses de nitrogênio $(\mathrm{N})$, e os respectivos coeficientes de determinação

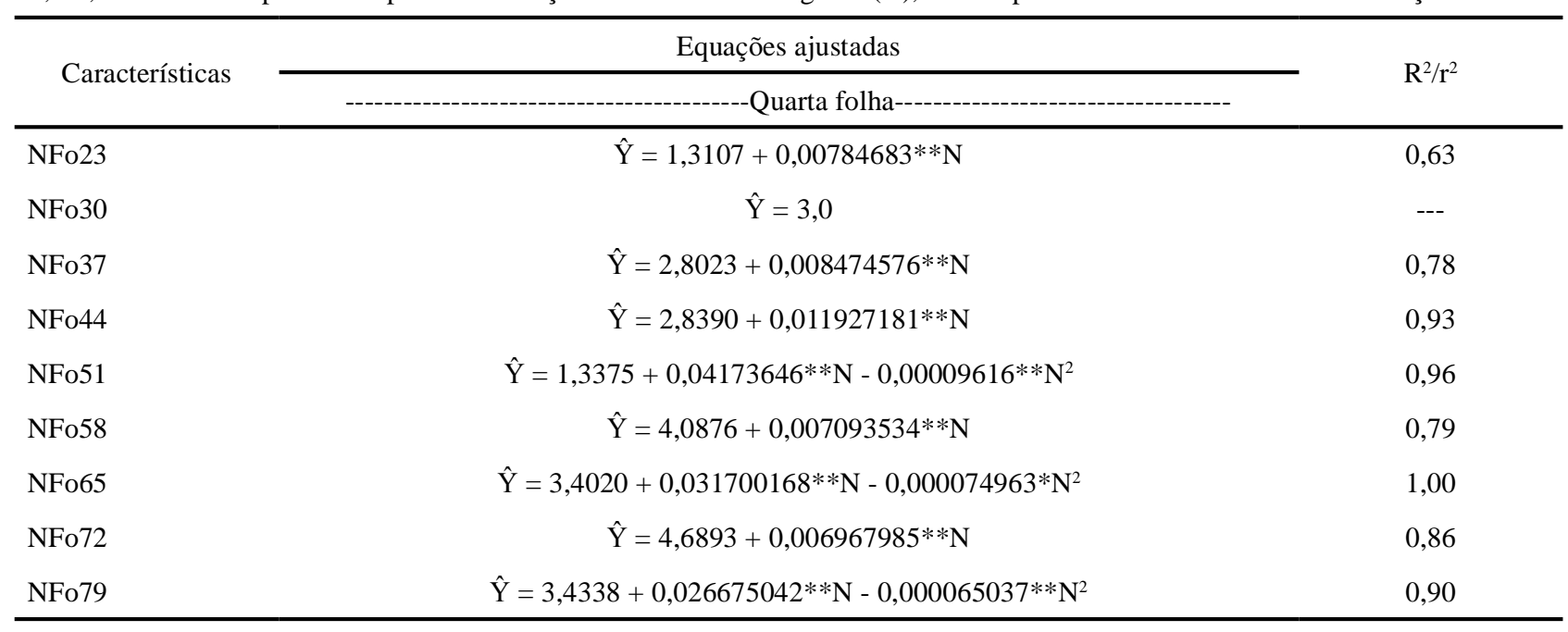


Continuação Tabela 5

\begin{tabular}{|c|c|c|}
\hline NFo23 & $\hat{Y}=1,0$ & --- \\
\hline NFo30 & $\hat{\mathrm{Y}}=1,0$ & --- \\
\hline NFo37 & $\hat{\mathrm{Y}}=2,0$ & --- \\
\hline NFo44 & $\hat{Y}=2,0$ & --- \\
\hline NFo51 & $\hat{\mathrm{Y}}=2,0$ & --- \\
\hline NFo58 & $\hat{\mathrm{Y}}=3,0$ & --- \\
\hline NFo65 & $\hat{\mathrm{Y}}=2,1215+0,004582549 * * \mathrm{~N}$ & 0,69 \\
\hline NFo72 & $\hat{\mathrm{Y}}=3,0$ & --- \\
\hline NFo79 & $\hat{\mathrm{Y}}=3,0$ & --- \\
\hline
\end{tabular}

** e* - significativos a 1 e $5 \%$ pelo teste "t", respectivamente

Tabela 6 - Equações ajustadas para o comprimento da haste $(\mathrm{CH})$ e número de folhas (NF) da batateira aos 23; 30; 37; 44; 51; 58; 65; 72 e 79 dias após o transplante, em função das doses de nitrogênio $(\mathrm{N})$, e os respectivos coeficientes de determinação

\begin{tabular}{|c|c|c|}
\hline Características & Equações ajustadas & $\mathrm{r}^{2}$ \\
\hline $\mathrm{CH} 23$ & $\hat{\mathrm{Y}}=4,5884+0,018512241 * * \mathrm{~N}$ & 0,92 \\
\hline $\mathrm{CH} 30$ & $\hat{\mathrm{Y}}=7,3944+0,0236283374 * * \mathrm{~N}$ & 0,80 \\
\hline CH37 & $\hat{\mathrm{Y}}=6,5071+0,046390458^{* *} \mathrm{~N}$ & 0,93 \\
\hline CH44 & $\hat{\mathrm{Y}}=8,4983+0,05234772 * * \mathrm{~N}$ & 0,94 \\
\hline CH51 & $\hat{\mathrm{Y}}=10,4144+0,05300691 * * \mathrm{~N}$ & 0,97 \\
\hline CH58 & $\hat{\mathrm{Y}}=10,7754+0,05441306^{* *} \mathrm{~N}$ & 0,97 \\
\hline CH65 & $\hat{\mathrm{Y}}=11,3344+0,05386692 * * \mathrm{~N}$ & 0,98 \\
\hline $\mathrm{CH} 72$ & $\hat{\mathrm{Y}}=11,6398+0,05519774 * * \mathrm{~N}$ & 0,98 \\
\hline CH79 & $\hat{\mathrm{Y}}=11,9647+0,05508475^{* *} \mathrm{~N}$ & 0,97 \\
\hline NF23 & $\hat{\mathrm{Y}}=3,0960+0,017576899 * * \mathrm{~N}$ & 0,90 \\
\hline NF30 & $\hat{\mathrm{Y}}=6,1582+0,015442561 * * \mathrm{~N}$ & 0,78 \\
\hline NF37 & $\hat{\mathrm{Y}}=7,3644+0,021155053^{* *} \mathrm{~N}$ & 0,93 \\
\hline NF44 & $\hat{\mathrm{Y}}=9,3644+0,021155053 * * \mathrm{~N}$ & 0,98 \\
\hline NF51 & $\hat{\mathrm{Y}}=16$ & --- \\
\hline NF58 & $\hat{\mathrm{Y}}=18$ & --- \\
\hline NF65 & $\hat{Y}=21$ & --- \\
\hline NF72 & $\hat{Y}=22$ & --- \\
\hline NF79 & $\hat{Y}=29$ & --- \\
\hline
\end{tabular}

** - significativo a 1 pelo teste " $\mathrm{t}$ "

$\mathrm{N}$ (Tabela 6). Com a dose de $\mathrm{N}$ que proporcionou o número máximo de tubérculos $\left(188,9 \mathrm{mg} \mathrm{L}^{-1}\right.$ de $\left.\mathrm{N}\right)$ o número de folhas atingiu, aos 79 DAT o valor ótimo estimado de 29 folhas/planta (Tabela 2). O número de folhas é influenciado pela disponibilidade de $\mathrm{N}$ para a planta, ou seja, dentro de certo limite quanto maior a quantidade de $\mathrm{N}$ fornecido à planta maior será o estímulo para a produção de folhas (ZVOMUYA et al., 2003). De acordo com Fontes (2011), deve ser possível estabelecer nível adequado ou crítico para as características agronômicas, sensíveis à 
aplicação de N. Dentre essas, a característica escolhida pode ser usada como índice indireto para a avaliação do estado nutricional em nitrogênio. Para a interpretação do valor obtido para determinada característica de planta é necessário que haja valor ou índice considerado referencial em determinado estádio fisiológico da planta (FONTES, 2011). A possibilidade de se utilizar um índice da planta como indicador da adequação da dose do fertilizante nitrogenado tem sido pouco explorada (FONTES; ARAÚJO, 2007). Segundo Fontes e Araújo (2007), talvez seja útil e eficiente a utilização conjunta de várias características fitotécnicas ou agronômicas reunidas na forma de índice, considerando que estas podem ser determinadas de forma fácil e não destrutiva.

A massa fresca da QF e FV foi influenciada pela aplicação de $\mathrm{N}$, o mesmo comportamento não ocorreu em relação à massa seca da FV (Tabela 7). O teor e o conteúdo de Norg na QF, na colheita final foram superiores aos valores obtidos na folha velha, e os valores obtidos aumentaram com o incremento da dose de N (Tabela 7). Comportamento semelhante foi verificado por Busato et al. (2010), em campo. Na FV, o teor e o conteúdo de $\mathrm{N}-\mathrm{NO}_{3}$ não foram influenciados pela aplicação de N (Tabela 7).

Na colheita final, realizada aos 79 DAT a massa da matéria fresca das raízes não foi influenciada pela aplicação de $\mathrm{N}$, enquanto que o número de tubérculos, área foliar e a massa da matéria seca de folhas, haste, raízes e tubérculos aumentaram com o incremento da dose de N (Tabela 8). Somente o número de tubérculos obteve resposta quadrática quanto à aplicação de $\mathrm{N}$, alcançando o valor máximo estimado de 14,1 unidades com a dose de $188,9 \mathrm{mg} \mathrm{L}^{-1}$ de $\mathrm{N}$ (Tabela 8). Por outro lado, a massa máxima de tubérculos não foi alcançada com a maior dose de $\mathrm{N}$, apresentando comportando linear e positivo com a aplicação de N. Dose de nitrogênio acima de $188,9 \mathrm{mg} \mathrm{L}^{-1}$ irá proporcionar maior desenvolvimento do tubérculos e da parte aérea em detrimento ao número de tubérculos. Como relatado anteriormente, a parte aérea respondeu de forma linear e positivamente com o incremento da dose de $\mathrm{N}$, o mesmo ocorreu com as massas da matéria fresca e seca de tubérculos por planta.

O número de tubérculos por planta (14,1 unidades) foi superior ao encontrado por Medeiros et al. (2002) que foi 11,5 tubérculos/planta. Factor et al. (2007) usando o mesmo sistema hidropônico utilizado nesse trabalho alcançaram 5,6 tubérculos/planta, enquanto Muller et al. (2007), obtiveram 3,6 tubérculos/planta no outono, utilizando o minitubérculo como material de propagação.

Com a dose de $\mathrm{N}$ que proporcionou o número máximo de tubérculos (188,9 $\mathrm{mg} \mathrm{L}^{-1}$ de $\mathrm{N}$ ), o valor ótimo estimado da massa da matéria seca de tubérculos foi de 13,81 g/planta. Novella et al. (2008), em plantas propagadas por minitubérculos encontraram a quantidade ótima de $\mathrm{N}$ para a produção de massa da matéria seca de tubérculos de $182 \mathrm{mg} \mathrm{L}^{-1}$. Muller et al. (2007) obtiveram respostas diferentes para produção de minitubérculos utilizando soluções com diferentes concentrações dos nutrientes dentre os quais o $\mathrm{N}$, em função da época de cultivo no sistema hidropônico.

Quanto à classificação dos tubérculos, a maior parte produzida ficou entre a classe V (16 a $23 \mathrm{~mm})$ e VIII (menor que $10 \mathrm{~mm}$ ), sendo que $33 \%$ foram classificados na classe VII (10 a $13 \mathrm{~mm}$ ). A utilização de espaçamento menor, $10 \mathrm{~cm}$ entre plantas determinou maior número de tubérculo por unidade de área e, com isso, pode

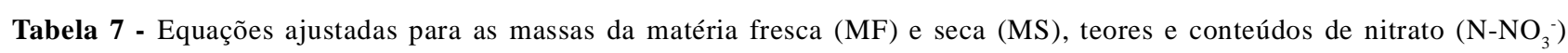
e nitrogênio orgânico $\left(\mathrm{N}_{\mathrm{org}}\right)$ na quarta folha $(\mathrm{QF})$ e folha velha $(\mathrm{FV})$ da batateira na colheita final, em função das doses de nitrogênio $(\mathrm{N})$, e os respectivos coeficientes de determinação

\begin{tabular}{|c|c|c|}
\hline Características & Equações ajustadas & $\mathrm{R}^{2} / \mathrm{r}^{2}$ \\
\hline MFQF (g) & $\hat{\mathrm{Y}}=0,1816+0,011733171 * * \mathrm{~N}-0,000028850 * * \mathrm{~N}^{2}$ & 1,00 \\
\hline $\operatorname{MFFV}(g)$ & $\hat{\mathrm{Y}}=0,4696+0,022470182 * * \mathrm{~N}$ & 0,69 \\
\hline MSQF (g) & $\hat{\mathrm{Y}}=-0,0078+0,002019175^{* *} \mathrm{~N}-0,000005122 * * \mathrm{~N}^{2}$ & 1,00 \\
\hline $\operatorname{MSFV}(\mathrm{g})$ & $\hat{\mathrm{Y}}=0,168$ & --- \\
\hline $\mathrm{N}-\mathrm{NO}_{3}-\mathrm{QF}\left(\right.$ dag g $\left.^{-1}\right)$ & $\hat{\mathrm{Y}}=-0,0039+0,0001046453 * * \mathrm{~N}$ & 0,83 \\
\hline $\mathrm{N}-\mathrm{NO}_{3}-\mathrm{FV}\left(\mathrm{dag} \mathrm{g}^{-1}\right)$ & $\hat{\mathrm{Y}}=0,000$ & --- \\
\hline $\mathrm{cN}-\mathrm{NO}_{3}-\mathrm{QF}(\mathrm{g} /$ planta $)$ & $\hat{\mathrm{Y}}=-0,0007+0,0000180414 * * \mathrm{~N}$ & 0,77 \\
\hline cN-NO $-\mathrm{FV}(\mathrm{g} /$ planta $)$ & $\hat{\mathrm{Y}}=0,002$ & --- \\
\hline
\end{tabular}

** - significativo a $1 \%$ pelo teste "t" 
Tabela 8 - Equações ajustadas para número de tubérculos (NT), área foliar (AF), massas das matérias fresca (MF) e seca (MS) das folhas $(F)$, hastes $(H)$, raízes $(R)$ e tubérculos $(T)$ em função das doses de nitrogênio $(\mathrm{N})$ e os respectivos coeficientes de determinação

\begin{tabular}{lcc}
\hline \multicolumn{1}{c}{ Características } & Equações ajustadas & $\mathrm{R}^{2} / \mathrm{r}^{2}$ \\
\hline NT (unidades/planta) & $\hat{\mathrm{Y}}=-2,3911+0,174962777 * * \mathrm{~N}-0,000463118^{* *} \mathrm{~N}^{2}$ & 0,86 \\
$\mathrm{AF}\left(\mathrm{cm}^{2} /\right.$ planta) & $\hat{\mathrm{Y}}=98,9597+1,46753735^{* * \mathrm{~N}}$ & 0,93 \\
MFF (g/planta) & $\hat{\mathrm{Y}}=8,5833+0,053781984^{* * \mathrm{~N}}$ & 0,66 \\
MFH (g/planta) & $\hat{\mathrm{Y}}=2,0736+0,017544884 * * \mathrm{~N}$ & 0,77 \\
MFR (g/planta) & $\hat{\mathrm{Y}}=2,576$ & --- \\
MFT (g/planta) & $\hat{\mathrm{Y}}=2,8438+0,240278468 * * \mathrm{~N}$ & 0,99 \\
MSF (g/planta) & $\hat{\mathrm{Y}}=1,0238+0,009680728^{* * \mathrm{~N}}$ & 0,79 \\
MSH (g/planta) & $\hat{\mathrm{Y}}=0,1808+0,0017868801^{* *} \mathrm{~N}$ & 0,76 \\
MSR (g/planta) & $\hat{\mathrm{Y}}=0,3500+0,0011288136^{*} \mathrm{~N}$ & 0,63 \\
MST (g/planta) & $\hat{\mathrm{Y}}=-2,5336+0,086504645 * * \mathrm{~N}$ & 0,91 \\
\hline
\end{tabular}

** - significativos a $1 \%$ pelo teste " $\mathrm{t}$ "

haver uma tendência de redução do tamanho médio dos tubérculos formados em comparação aos desenvolvidos em espaçamentos maiores (MEDEIROS et al., 2002).

\section{CONCLUSÕES}

1.O nitrogênio influencia positivamente o número e a massa de tubérculos produzidos e também os índices fisiológicos, tanto da quarta folha quanto da folha velha;

2.Número e massa fresca de tubérculos por planta não são otimizados pela mesma dose de $\mathrm{N}$. O número máximo de tubérculos por planta (14,1 unidades) é obtido com 188,9 $\mathrm{mg} \mathrm{L}^{-1}$ de $\mathrm{N}$. A maior massa de tubérculos por planta $(68,4 \mathrm{~g})$ é obtida com a maior dose de $\mathrm{N}$;

3.O índice crítico SPAD na quarta folha é variável com a idade da planta sendo de 38,4 o maior valor atingido aos 58 DAT.

\section{AGRADECIMENTOS}

Ao Conselho Nacional de Desenvolvimento Científico e Tecnológico (CNPq) pelas bolsas de mestrado e pós-doutorado e à FAPEMIG pelo recurso financeiro.

\section{REFERÊNCIAS}

ANDRIOLO, J. L. Sistema hidropônico fechado com subirrigação para produção de minitubérculos de batata. In: Simpósio de Melhoramento Genético e Previsão de Epifitias em Batata. 2006, Santa Maria. Anais... Santa Maria, 2006. p. 26-40.

ANDRIOLO, J. L. et al. Curva crítica de diluição de nitrogênio da cultivar Asterix de batata. Pesquisa Agropecuária Brasileira, v. 41, n. 7, p. 1179-1184, 2006.

BRAUN, H. et al. Effect of nitrogen rates and days of light exposure on greening evaluated by visual scale and chlorophyll meter of tubers of potato cultivars. International Journal of Food, Agriculture and Environment, v. 8, n. 3/4, p. 933-938, 2010.

BRYAN, J. E.; MELÉNDEZ, G.; JACKSON, M. T. Esquejes de brote, uma técnica de multiplicação rápida de papa. Técnicas de multiplicación rápida.Lima: Centro Internacional de La Papa. 1981. 10 p.

BUSATO, C. et al. Seasonal Variation and Threshold Values for Chlorophyll Meter Readings on Leaves of Potato Cultivars. Journal of Plant Nutrition, v. 33, n. 14, p. 2148-2156, 2010.

CARDOSO, A. D. et al. Índice SPAD no limbo foliar da batateira sob parcelamentos e doses de nitrogênio e potássio. Revista Ciência Agronômica, v. 42, n. 1, p. 159-167, 2011.

CATALDO, D. A. et al. Rapid colorimetric determination of nitrate in plant tissue by nitration of salicylic acid. Communications in Soil Science and Plant Analysis, v. 6, n. 1, p. 71-80, 1975.

COELHO, F. S. et al. Dose de nitrogênio associada à produtividade de batata e índices do estado de nitrogênio na folha. Revista Brasileira Ciência do Solo, v. 34, n. 4, p. 1175-1183, 2010.

CORREAA, R. M. et al. The production of seed potatoes by hydroponic methods in Brazil. Fruit, Vegetable and Cereal Science and Biotechnology, v. 3, p. 133-139, 2009.

CORRÊA, R. M. et al. A comparison of potato seed tuber yields in beds, pots ams hydroponic systems. Scientia Horticulturae, v. 116, n. 1, p. 17-20, 2008. 
FACTOR, T. L. et al. Produção de minitubérculos básicos de batata em três sistemas hidropônicos. Horticultura Brasileira, v. 25, n. 1, p. 82-87, 2007.

FONTES, P. C. R. Nutrição Mineral de Plantas: avaliação e diagnose. Arka Editora, 2011. 296 p.

FONTES, P. C. R.; ARAÚJO, C. Adubações nitrogenadas de hortaliças - princípios e práticas com o tomateiro. Viçosa: Editora UFV, 2007, 148 p.

FONTES, P. C. R. et al. Economic Optimum Nitrogen Fertilization Rates and Nitrogen Fertilization Rate Effects on Tuber Characteristics of Potato Cultivars. Potato Research, v. 53, n. 3 , p. $1-2,2010$.

INSTITUTO MINEIRO DE AGROPECUÁRIA. Portaria n.567, 30 de janeiro de 2003. Disponível em: <http://imanet. ima.mg.gov.br/nova/legis/portarias_pdf/0567.pdf>. Acesso em: 20 mar. 2007.

JACKSON, M. L. Soil chemical analysis. Englewood Cliffs: Prentice Hall, 1958. 498 p.

MEDEIROS C. A. B. et al. Estrutura de sistema hidropônico para produção de sementes pré-básicas de batata. Pelotas: Embrapa Clima Temperado, 2000. 10 p. (Comunicado Técnico, n. 29).

MEDEIROS, C. A. B.; CUNHA, B. P. Cultivo hidropônico de sementes pré-básicas de batata: concentração de nitrogênio na solução nutritiva. Horticultura Brasileira, v. 21, n. 2, p. 372, 2003.

MEDEIROS, C. A. B. et al. Produção de sementes pré-básicas de batata em sistemas hidropônicos. Horticultura Brasileira, v. 20, n. 1, p. 110-114, 2002.

MOREIRA, M. A. et al. Seleção de índices para o diagnóstico do estado de nitrogênio de batata-semente básica. Acta Scientiarum. Agronomy, v. 33, n. 2, p. 335-340, 2011.

MULLER, D. R. et al. Produção hidropônica de batata em diferentes concentrações de solução nutritiva e épocas de cultivo. Pesquisa Agropecuária Brasileira, v. 42, n. 5, p. 647-653, 2007.

NOVELLA, M. B. et al. Concentration of nutrient solution in the hydroponic production of potato minitubers. Ciência Rural, v. 38, n. 6, p. 1529-1533, 2008.

RASTAMI, M. et al. Evaluation of chlorophyll meter (SPAD) data for prediction of nitrogen status in corn (Zea mays L.). AmericanEurasian Journal Agriculture Science, v. 3, p. 79-85, 2008.
RODRIGUES, M. A. Establishment of continuous critical levels for indices of plant and presidedress soil nitrogen status in the potato crop. Communications in Soil Science and Plant Analysis, v. 35, n. 13/14, p. 2067-2085, 2004.

SAMPAIO JÚNIOR, J. D. et al. Produção de mini-tubérculo semente de batata, em função de doses de nitrogênio aplicadas ao substrato. Bioscience Journal, v. 26, n. 1, p. 1-9, 2008.

SILVA, E. C.; GIUSTO, A. B.; SOUSA DIAS, J. A. C. Produção de minitubérculos a partir de brotos de cultivares de batata em diferentes combinações de substratos. Horticultura Brasileira, v. 24, p. 241-244, 2006.

SILVA, M. C. C. et al. Índice SPAD determinado em diferentes horários e posições no folíolo da batata sob fertilização nitrogenada. Revista Ciência Agronômica, v. 42, n. 4, p. 971-977, 2011.

SILVA, M. C. C.; FONTES, P. C. R.; MIRANDA, G. V. Índices SPAD e produção de batata, em duas épocas de plantio, em função de doses de nitrogênio. Horticultura Brasileira, v. 27, n. 1, p. 17-22, 2009.

SISTEMA para Análises Estatísticas. Versão 9.1. Viçosa: Fundação Arthur Bernardes - UFV, 2007.

SOUZA-DIAS, J. A. C. Caruaru (PE) e Esperança (PB): Redutos para a Tecnologia APTA-IAC do Broto/Batata-Semente na Produção de Batata-Semente "Classe Básica". Batata Show, ano 6, n. 15, p. 12-13, 2006a.

SOUZA-DIAS, J. A. C. Tecnologia de produção de minitubérculos de batata-semente pré-básica, através do plantio de brotos livres de vírus. Batata Show, ano. 4, n. 9, p. 7, 2004.

SOUZA-DIAS, J. A. C. Tecnologia do Broto/Batata-semente: uma ideia que está brotando na bataticultura. O Agrário, v. 7, p. 7, 2006b.

WU, J. et al. Comparison of petiole nitrate concentrations, SPAD chlorophyll readings, and QuickBird satellite imagery in detecting nitrogen status of potato canopies. Field Crops Research, v. 101, p. 96-103, 2007.

ZVOMUYA, F. et al. Nitrate leaching and nitrogen recovery following application of polyolefin-coated urea of potato. Journal of Environmental quality, v. 32, n. 2, p. 480-489, 2003. 